\title{
Copper Delivery to Chloroplast Proteins and its Regulation
}

\author{
Guadalupe Aguirre and Marinus Pilon* \\ Biology Department, Colorado State University, Fort Collins, CO, USA
}

Copper is required for photosynthesis in chloroplasts of plants because it is a cofactor of plastocyanin, an essential electron carrier in the thylakoid lumen. Other chloroplast copper proteins are copper/zinc superoxide dismutase and polyphenol oxidase, but these proteins seem to be dispensable under conditions of low copper supply when transcripts for these proteins undergo microRNA-mediated down regulation. Two ATP-driven copper transporters function in tandem to deliver copper to chloroplast compartments. This review seeks to summarize the mechanisms of copper delivery to chloroplast proteins and its regulation. We also delineate some of the unanswered questions that still remain in this field.

Keywords: plastocyanin, photosynthesis, copper deficiency, copper transporting P-type ATPase, polyphenol oxidase, superoxide dismutase, $\mathrm{Cu}$-miRNA

\section{INTRODUCTION}

OPEN ACCESS

Edited by: Cornelia Spetea, University of Gothenburg, Sweden

Reviewed by: Olena Vatamaniuk, Cornell University, USA

Marc Hanikenne,

University of Liège, Belgium

${ }^{*}$ Correspondence:

Marinus Pilon

pilon@colostate.edu

Specialty section: This article was submitted to Plant Physiology, a section of the journal

Frontiers in Plant Science

Received: 30 October 2015 Accepted: 21 December 2015

Published: 12 January 2016

Citation: Aguirre G and Pilon M (2016) Copper Delivery to Chloroplast Proteins and its Regulation.

Front. Plant Sci. 6:1250. doi: 10.3389/fpls.2015.01250
It is estimated that at least a third of all known proteins require a metal cofactor (Waldron et al., 2009). Copper ( $\mathrm{Cu})$ is essential for most living organisms including higher plants. In living cells $\mathrm{Cu}$ is predominantly found in two redox states, $\mathrm{Cu}^{2+}$ (cupric) and $\mathrm{Cu}^{+}$(cuprous). The utility of $\mathrm{Cu}$ is related to its capacity to switch redox states in the cellular environment (i.e., become oxidized and reduced while bound to a protein) and the majority of $\mathrm{Cu}$ proteins $(\sim 90 \%)$ found in nature function as oxidoreductases (Waldron et al., 2009). In green tissue of plants a large fraction of the $\mathrm{Cu}$ is present within the chloroplasts, corresponding to roughly a third of the $\mathrm{Cu}$ in leaves of soilgrown, well-fertilized, Arabidopsis thaliana (Shikanai et al., 2003). The fraction of $\mathrm{Cu}$ in a leaf that is allocated to plastids probably varies with $\mathrm{Cu}$ supply, however, (Burkhead et al., 2009). In this review we aim to describe the mechanism of $\mathrm{Cu}$ delivery to chloroplast proteins and its regulation. Emphasis is given on new models and outstanding questions.

\section{CHLOROPLAST COPPER PROTEINS}

In chloroplasts, three major $\mathrm{Cu}$ proteins have been described (see Figure 1). In the stromal compartment, an isoform of copper/zinc superoxide dismutase is active. The enzyme is encoded by the CSD2 gene in Arabidopsis thaliana (Kliebenstein et al., 1998). CSD2 maturation has an absolute requirement for a conserved CCS called CCS (Abdel-Ghany et al., 2005b; Chu et al., 2005; Huang et al., 2012) which functions to deliver and insert $\mathrm{Cu}$ into this enzyme. In contrast, the major cytosolic isoform of copper/zinc superoxide dismutase (CSD1 in Arabidopsis) can mature without CCS, albeit with low efficiency (Huang et al., 2012). Although copper/zinc superoxide

Abbreviations: CCO, Cytochrome-c oxidase; CCS, Copper chaperone for SOD; CSD, Cu/ZnSOD or Cu/Zn-superoxide dismutase; HMA, Heavy Metal ATPase; PAA, P-type ATPase of Arabodopsis; PC, Plastocyanin; PPO, polyphenol oxidase; SPL7, Squamosa Promotor binding-Like 7. 


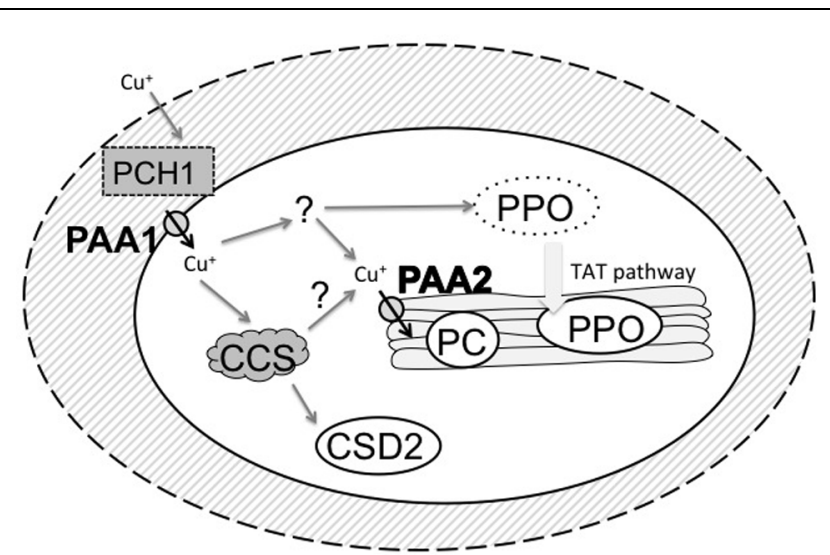

PAA1/PAA2 Cu-transporters

FIGURE 1 | Chloroplast copper proteins and delivery systems. CSD2 (copper/zinc superoxide dismutase) is active in the stroma and receives $\mathrm{Cu}$ ions from CCS (the copper chaperone for superoxide dismutase). PC is active in the thylakoid lumen. PPO is found in the thylakoid lumen but may receive its $\mathrm{Cu}$ ion in the stroma before entering the thylakoid space via the TAT protein translocation pathway. PAA1 is a copper transporter in the envelope required to supply $\mathrm{Cu}$ ions to CSD2, PC and presumably also PPO. PAA1 receives $\mathrm{Cu}$ ions from the plastid copper chaperone 1 ( $\mathrm{PCH} 1)$. Cu ions may reach $\mathrm{PCH} 1$ in the inter membrane space of the envelope via diffusion through porins in the outer membrane, perhaps bound to low molecular weight chelators such as glutathione. Alternatively, $\mathrm{PCH} 1$ might pick up $\mathrm{Cu}$ ions in the cytosol and diffuse in via pores in the outer membrane. PAA2 is a homologs copper transporter in the thylakoid membrane required to deliver $\mathrm{Cu}$ ions to PC. A protein donating $\mathrm{Cu}$ ions to PAA2 has not been identified yet.

dismutases are highly conserved in plants and other eukaryotes, their biological significance in plants has been elusive. A report of strong phenotypes for a loss of function (knock-down) mutant of CSD2 (Rizhsky et al., 2003) was in retrospect based on a insertion mutant that upon further study did not seem to affect CSD2 protein expression at all (Cohu et al., 2009). Phenotypes of CCS loss-of function mutants, which have no detectable CSD2 activity and very low CSD1 activity, are very mild when compared to the wild-type (Dugas and Bartel, 2008; Cohu et al., 2009) or require extreme stress to become noticeable (Sunkar et al., 2006). Redundancy with chloroplastic FeSOD may be one factor affecting $\mathrm{Cu} / \mathrm{ZnSOD}$ loss of function phenotypes (Cohu et al., 2009). The green alga Chlamydomonas reinhardtii does not encode for $\mathrm{Cu} / \mathrm{ZnSOD}$ but it contains FeSOD in the chloroplast.

Plastocyanin is a small $\mathrm{Cu}$ protein in the thylakoid lumen and serves as an electron carrier between the cytochrome- $b_{6} f$ complex and PSI in plants and is essential for photo-autotrophic growth in plants (Weigel et al., 2003). In contrast, similar to some cyanobacteria, Chlamydomonas can use the heme-containing cytochrome- $\mathrm{c}_{6}$ when $\mathrm{Cu}$ becomes limiting, as an alternative to PC (Kropat et al., 2015). In most plant genomes including Arabidopsis and poplar two PC isoforms are encoded. The two isoforms have essentially equivalent function regarding electron transport activity but in Arabidopsis one protein isoform (PC1) accumulates at a lower level whereas a second isoform (PC2) is much more abundant but also more sensitive to $\mathrm{Cu}$ availability at the protein level (Abdel-Ghany, 2009; Pesaresi et al., 2009). In poplar, both PC isoforms seem to be expressed at a comparable level (Ravet et al., 2011). PC was the first plant $\mathrm{Cu}$ enzyme that was cloned and its biogenesis is very well studied. The PC precursor has a bipartite $\mathrm{N}$-terminal targeting sequence consisting of first a transit peptide, which functions to bring the protein into the stroma, followed by a signal sequence that serves for interaction with the ATP-dependent SEC machinery for translocation to the thylakoid lumen (Smeekens et al., 1986). Because protein transport over the envelope and thylakoid membranes via the SEC pathway requires unfolded polypeptide substrates, $\mathrm{Cu}$ must insert into apo-PC in the thylakoid lumen (for a review on chloroplast protein transport see Jarvis, 2008).

A third abundant $\mathrm{Cu}$ enzyme is PPO, also known as tyrosinase, which is present in the thylakoid lumen of many plants including poplar and spinach where it was discovered as the first $\mathrm{Cu}$ enzyme in plants (Arnon, 1949). However, PPO is absent from Arabidopsis (Schubert et al., 2002) and Chlamydomonas. The $\mathrm{PPO}$ enzymes contain $2 \mathrm{Cu}$ atoms per monomer. In vitro, $\mathrm{PPO}$ can catalyze the formation of ortho-diphenols or ortho quinones from mono-phenols or ortho-dihydroxyphenols (See Mayer, 2006). The PPO substrates are not found in the thylakoid lumen, but are stocked in other cellular compartments such as vacuoles, and cell disruption by herbivory would allow PPO to form the dark-brown colored products in disrupted cells that make plant tissue less digestible (Mayer, 2006). Thus, PPO is thought to function in defense to herbivory or pathogen attack (Constabel et al., 2000; Wang and Constabel, 2004). As is the case with PC, the PPO precursors contain a bipartite targeting sequence at their N-terminus, but in the case of PPOs the thylakoid transfer sequence contains the twin arginine sequence motif, which means that PPO should use the TAT system for thylakoid transfer (see Jarvis, 2008). Because the TAT system can translocate folded peptides this implies that PPO might acquire its two $\mathrm{Cu}$ atoms in the stroma.

\section{PRINCIPLES OF COPPER HOMEOSTASIS}

It helps to understand chloroplast $\mathrm{Cu}$ transport in the context of overall $\mathrm{Cu}$ homeostasis and the properties of $\mathrm{Cu}$ ions. Among biologically active metal ions, copper binds the most tightly to its ligands. Both cupric and cuprous ions bind tightly to $S$ and N-containing ligands (Irving and Williams, 1948; Waldron et al., 2009). These ligands are abundant in the cytosol, either as parts of amino acid functional groups in proteins (particularly cysteine, methionine, and histidine) or in low molecular weight compounds such as glutathione (cysteine). Within the reducing environment of the cytosol, free thiols in proteins and glutathione are especially strong ligands for $\mathrm{Cu}^{+}$ions (Waldron et al., 2009). Therefore, the cytosol will have a very high chelating capacity for $\mathrm{Cu}$ ions when compared to an extracellular or exoplasmic compartment (e.g., vacuole) and indeed only very low free $\mathrm{Cu}$ ion concentrations are found inside cells (Rae et al., 1999). The very high cellular chelation capacity for $\mathrm{Cu}$ means that effectively a concentration gradient for free $\mathrm{Cu}$ ions should exist over the 
plasma membrane with a relatively low free $\mathrm{Cu}$ concentration in the cytosol, and this should help to provide a driving force for $\mathrm{Cu}$ ion uptake from the extracellular space. Conversely, export of $\mathrm{Cu}$ ions from the cytosol or a compartment with similar properties such as the chloroplast stroma should require metabolic energy. The strong tendency of $\mathrm{Cu}$ to bind to intracellular sites also makes it possible for $\mathrm{Cu}$ ions to replace other metals, causing toxicity. For this reason and in order to ensure correct delivery of $\mathrm{Cu}^{+}$, intracellular $\mathrm{Cu}$-chaperones exist which scavenge $\mathrm{Cu}^{+}$ and deliver it to specific targets via protein-protein interactions. Finally, sensors that control $\mathrm{Cu}$ homeostasis should have a high affinity for the ion.

\section{CELLULAR COPPER TRANSPORTERS}

Before turning to chloroplast-specific transport we want to first give a brief overview of cellular $\mathrm{Cu}$ transport and regulation because this affects the chloroplast also. Four classes of transporters have been implicated in $\mathrm{Cu}$ transport: COPT, ZIP, YSL, and HMA (see Williams et al., 2000; Burkhead et al., 2009).

\section{Roles of COPT, ZIP, and YSL Transporters}

Copper enters eukaryotic cells by means of the CTR $\mathrm{Cu}$ transporters. The Arabidopsis genome contains six CTR-like sequences, which are called COPT1-6. COPT4 does not seem to be active (Sancenon et al., 2003). COPT 1, 2, and 6 are likely active at the cell surface (Sancenón et al., 2004; Jung et al., 2012), COPT3 may be active in an internal membrane and COPT5 is active in the tonoplast (Garcia-Molina et al., 2011; Klaumann et al., 2011). CTR/COPT transporters likely function as channels or carriers specific for $\mathrm{Cu}^{+}$where the direction of transport is toward the cytoplasm (Eisses and Kaplan, 2005). The driving force for $\mathrm{Cu}^{+}$uptake can be provided by both the strong capacity of the cytosol for $\mathrm{Cu}^{+}$chelation as well as the typical orientation of the membrane potential, which is positively charged on the exoplasmic side due to proton exporting pumps. In the case of plant cells, reductases of the FRO family
(Fro4/5) facilitate $\mathrm{Cu}$ uptake by reducing extracellular $\mathrm{Cu}^{2+}$ to $\mathrm{Cu}^{+}$, providing COPT proteins with a substrate (Bernal et al., 2012).

Whereas the role of COPT transporters is fairly well delineated, the picture is far less clear for the ZIP (Zrt and Irt like proteins; divalent metal transporters) and YSL (Yellow Stripe Like) transporter families. ZIP2 is clearly upregulated by $\mathrm{Cu}$ deficiency (Wintz et al., 2003; Bernal et al., 2012). ZIP2 and ZIP4 were reported to complement a yeast ctr1 Cu uptake mutant (Wintz et al., 2003) but this result was not reproduced for ZIP2 in a more recent study, which instead indicated ZIP2 functions in $\mathrm{Zn}$ and Mn transport (Milner et al., 2013). The Yellow Stripe-Like (YSL) metal transporters, which were first identified in corn, are involved in the long-distance transport of metal-bound nicotianamine in Arabidopsis and rice (Waters et al., 2006; Chu et al., 2010; Zheng et al., 2012). For YSL family members YSL1, 2 and 3 roles in redistribution of $\mathrm{Cu}$ from leaves during senescence have been reported (Waters et al., 2006; Chu et al., 2010). YSL2 is strongly up-regulated in $\mathrm{Cu}$ deficiency at the transcript level in an SPL7-dependent process (Bernal et al., 2012). In excess-copper conditions, YSL1 and YSL3 proteins are down-regulated through sumoylation in Arabidopsis (Chen et al., 2011).

\section{HMA Transporters}

An important class of $\mathrm{Cu}$ transporters is formed by a subclass of the metal transporting P1b-type ATPases or HMA proteins as they are called in plants (Williams et al., 2000; Hanikenne and Baurain, 2014). A schematic model for this type of transporter is given in Figure 2. Members of this family of transporters exist in two conformational states called E1 and E2. In all mechanistically studied P-type ATPases, hydrolysis of ATP after substrate binding is utilized to convert the E1 form of the enzyme to the E2 state in which a conserved ASP residue is phosphorylated. Subsequent release of the substrate on the trans side allows for phosphatase activity, which brings the enzyme back to the E1 state (for review see Rosenzweig and Argüello, 2012). In virtually all known P-type ATPases the ATP is bound on the cytoplasmic side and the substrates are exported from

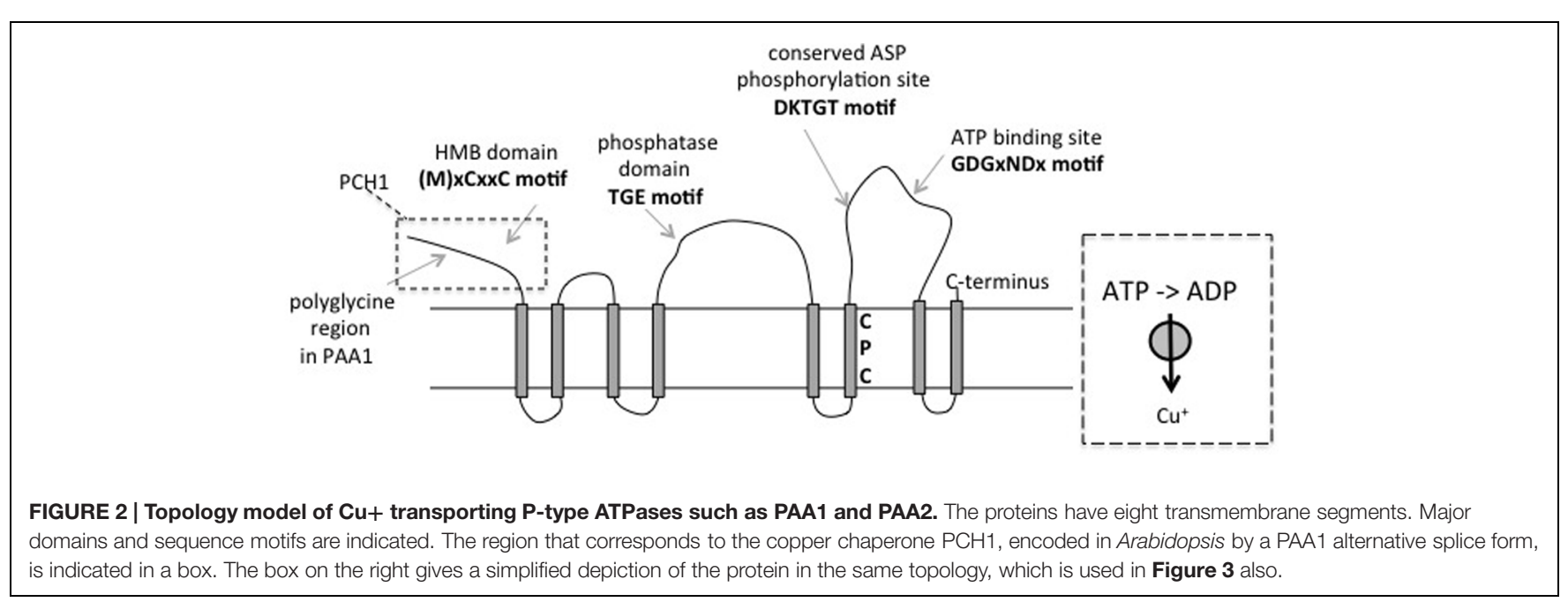


there (Rosenzweig and Argüello, 2012). The sequence motif CPC in $\mathrm{TM}$ region 6 is characteristic for $\mathrm{Zn}$ and $\mathrm{Cu}$ transporters (Hanikenne and Baurain, 2014). The specificity for $\mathrm{Cu}^{+}$substrate is further determined by specific sequences in transmembrane regions 7 and 8 (Mandal et al., 2004). In other classes of P-type ATPases, the energy released by ATP hydrolysis can be used to pump ions such as $\mathrm{H}^{+}, \mathrm{Ca}^{2+}$, and $\mathrm{Na}^{+}$against steep electrochemical gradients. In the cases of $\mathrm{Zn}$ and $\mathrm{Cu}$ it is evident that such large concentration gradients do not exist. However, the high chelating capacity of the cytosol for $\mathrm{Zn}$ and $\mathrm{Cu}$ ions presents a sizable thermodynamic barrier for export, which necessitates the utilization of metabolic energy for the transport of these ions from this compartment. Specific metallo chaperones are used to sequester the correct ion in the cytosol and deliver it to the cognate metal transporter via ligand exchange (Rosenzweig and Argüello, 2012). One of the best characterized $\mathrm{Cu}$ chaperones is ATX (anti-oxidant) from yeast, which has a ferredoxin-like fold and contains the consensus $\mathrm{Cu}$ binding motif MxCxxC. All $\mathrm{Cu}$ chaperones for P1B-type ATPases are similar and therefore this type of chaperone is called ATX-like (Pufahl et al., 1997). Most metal transporting P-type ATPases have one or more N-terminal heavy metal-binding (HMB) domain(s) which are also known as metal binding domains (MBD; (Hanikenne and Baurain, 2014). For $\mathrm{Cu}^{+}$transporters these domains are structurally similar to ATX (Rosenzweig and Argüello, 2012). Work with bacterial $\mathrm{Cu}^{+}$transporters has indicated that the HMB domain can accept metal from a ATXlike metallochaperone with a similar ferredoxin fold structure. Because the transporters maintain ATPase and transport activity without the HMB domain, and because this domain was shown to be inhibitory for ATPase activity in some cases, it can be proposed that the function of the HMB domain in vivo is perhaps regulatory (Rosenzweig and Argüello, 2012), but this has not been addressed in plants. The $\mathrm{Cu}$ chaperones that function with $\mathrm{Cu}$-transporting ATPases bind via electrostatic interactions with a platform formed by a loop associated with transmembrane region 2 of the transporter and deliver sequentially two $\mathrm{Cu}^{+}$ions directly to the transmembrane domains 6-8 that harbor the metal binding/transport sites (González-Guerrero and Argüello, 2008; Rosenzweig and Argüello, 2012).

Eight metal transporting P-Type ATPases are encoded in the Arabidopsis genome with homologs in most green eukaryotes (Williams et al., 2000; Hanikenne and Baurain, 2014). For four of the Arabidopsis HMA proteins a direct role in $\mathrm{Cu}$ homeostasis has been shown. HMA7 transports $\mathrm{Cu}$ from the cytoplasm to an endomembrane compartment where it can associate with the $\mathrm{Cu}$ binding site of the ethylene receptors (Hirayama et al., 1999). HMA5 in the plasma membrane removes $\mathrm{Cu}$ from the cell to allow xylem loading in the roots and prevent cellular $\mathrm{Cu}$ overload (Andres-Colas et al., 2006). HMA5 and 7 are likely to receive $\mathrm{Cu}$ from the ATX and or $\mathrm{CCH}$ cytosolic $\mathrm{Cu}$ chaperones for which interaction has been shown using yeasttwo-hybrid assays (Puig et al., 2007). Two $\mathrm{Cu}$ transporting P-Type ATPases, PAA1/HMA6 and PAA2/HMA8 have been localized in plastids and these are described in more detail further below together with HMA1 a third ATP-driven metal transporter in the chloroplast.

\section{COPPER HOMEOSTASIS}

Because it affects chloroplast $\mathrm{Cu}$ transport pathways, it is necessary to briefly discuss cellular $\mathrm{Cu}$ homeostasis. When cellular $\mathrm{Cu}$ levels drop, a conserved transcription factor called SPL7 (Squamosa Promoter binding-Like 7) activates the transcription of a set of genes that together mediate a response to low Cu (Yamasaki et al., 2009). SPL7 in plants shares sequence similarity with Chlamydomonas CRR1 (the Copper Response Regulator) and activates transcription of genes that have a $\mathrm{Cu}$ Response element (CuRe) with the consensus sequence GTAC in it (Kropat et al., 2005; Yamasaki et al., 2009). SPL7 targets include several of the COPT transporters (COPT 1, 2, 6) and the potential cupric reductases FRO4 and 5 (Yamasaki et al., 2009; Bernal et al., 2012). Several highly conserved microRNAs, together called the Cu-microRNAs are also targets of SPL7 (Yamasaki et al., 2009; Bernal et al., 2012). These microRNAs in turn down-regulate the expression of $\mathrm{Cu}$ proteins including CSD2 and the PPOs (Yamasaki et al., 2007; Abdel-Ghany and Pilon, 2008; Cohu et al., 2009; Ravet et al., 2011). Since PC is not a target of a CumicroRNA it can be hypothesized that the Cu-microRNAs serve to maintain a larger pool of $\mathrm{Cu}$ available for PC maturation, which is essential for photosynthesis (Burkhead et al., 2009). MiR398 targets CSD1, CSD2, and CCS as well as COX5b, a potential subunit of mitochondrial CCO but not a part of the Cu-binding core of this enzyme (Yamasaki et al., 2007). Mir397 and MiR408 target laccases and MiR408 also targets apoplastic plantacyanin (Abdel-Ghany and Pilon, 2008). MiR1444 targets PPO isoforms (Ravet et al., 2011). In Chlamydomonas, no miRNA regulation of $\mathrm{Cu}$ proteins exists but CRR1 regulates $\mathrm{Cu}$ economy by promoting the expression of cytochrome- $c_{6}$ and turnover of PC; further transcriptional regulation by CRR1 aims to further economize $\mathrm{Cu}$ use and optimize $\mathrm{Fe}$ acquisition in Chlamydomonas (Kropat et al., 2005, 2015).

\section{COPPER TRANSPORT TO CHLOROPLAST PROTEINS}

In the chloroplast two conserved $\mathrm{Cu}$ transporters have been identified (Figure 1). PAA1/HMA6 is localized in the chloroplast envelope (Shikanai et al., 2003; Catty et al., 2011). PAA2/HMA8 is localized in the thylakoids (Abdel-Ghany et al., 2005a). GFP fusions (Abdel-Ghany et al., 2005b), proteomic data (Catty et al., 2011; Tomizioli et al., 2014), and direct biochemical localization data, (Blaby-Haas et al., 2014) support the localization of these two proteins in Arabidopsis. In addition, PAA2/HMA8 was observed by immune EM in thylakoids in soybean (Bernal et al., 2007). Both PAA1 and PAA2 display all the characteristic motifs and domains expected for a Cu-transporting P-type ATPase (Abdel-Ghany et al., 2005a). A schematic structure is depicted in Figure 2. Phenotypes of Arabidopsis mutants indicated that both transporters are required for efficient maturation of PC, whereas only PAA1 is required for CSD2 activity. In addition, PAA1 mutants have lower $\mathrm{Cu}$ content in the entire chloroplast whereas PAA2 mutants have lowered $\mathrm{Cu}$ in the thylakoids (Abdel-Ghany et al., 2005a). Thus the two transporters function in tandem, 
as indicated in Figure 1. Homologs of PAA1 and PAA2 are present in eukaryotic green organisms including Chlamydomonas (Hanikenne and Baurain, 2014).

As discussed above, Cu-transporting P-type ATPases are expected to transport $\mathrm{Cu}$ away from the ATP binding site and to accept $\mathrm{Cu}$ from a metallo- chaperone. For PAA1 the topology in the inner envelope has been determined, which showed that the protein has its ATP binding site and thus also its substrate binding site on the intermembrane space side of the inner envelope membrane (Blaby-Haas et al., 2014). In Arabidopsis, two major splice forms are found for the PAA1 mRNA. One splice form, the full length mRNA, encodes for the full transporter. A second splice form is truncated and has an early stop codon, which leads in translation to a protein that only includes the transit peptide and HMB domain (Blaby-Haas et al., 2014). Since HMB domains are structurally very similar to $\mathrm{Cu}$-chaperones it was proposed that this splice form encodes a chloroplast $\mathrm{Cu}$ chaperone called $\mathrm{PCH} 1 . \mathrm{PCH} 1$ is conserved, in some plants it is formed from the alternative splice form of PAA1; in other plants gene duplication allowed a PAA1 sequence to evolve to encode the chaperone. Immunoblot analyses showed that the small $\mathrm{Cu}$ chaperone indeed is present in plants (Blaby-Haas et al., 2014). Direct biochemical measurements of ATPase activity for purified recombinant PAA1 and PAA2 showed that PCH1 can donate $\mathrm{Cu}$ to PAA1 but not to PAA2. Thus PCH1 seems to function in $\mathrm{Cu}$ delivery to PAA1 in the envelope intermembrane space of the chloroplast (BlabyHaas et al., 2014). For PAA2 the topology is not determined directly. PAA2 functions to provide $\mathrm{Cu}$ to the lumen and thus we can expect PAA2 to have its ATP binding site in the stroma.

No regulation of transcript or protein levels has been observed in response to $\mathrm{Cu}$ availability for PAA1. For PAA2, however, regulation has been observed at the post-translational level. When Arabidopsis is grown on media with elevated $\mathrm{Cu}$, much less PAA2 protein accumulates (Tapken et al., 2012). The mRNA of PAA2 is not affected by $\mathrm{Cu}$ feeding of plants, but instead $\mathrm{Cu}$ feeding mediates the turnover of the PAA2 protein via the conserved stromal CLP protease system (Tapken et al., 2015a). The observation that PAA2 is more stable in paa1 mutants suggests that PAA2 turnover requires $\mathrm{Cu}$ in the chloroplast (Tapken et al., 2012). Interestingly, loss of pc2 resulted in increased PAA2 turnover Tapken et al. (2012). In a paa1/pc2 double mutant, however, the regulation of PAA2 turnover was maintained similar to the wild type (Tapken et al., 2015b). Thus PC2 protein itself is not involved in PAA2 regulation. The CLP complex does not seem to be regulated by $\mathrm{Cu}$ (Tapken et al., 2015a). Rather, it can be proposed that PAA2 in association with $\mathrm{Cu}$ is more susceptible to turnover and this state is promoted by elevated $\mathrm{Cu}$ availability in the stroma or the absence of a $\mathrm{Cu}$ acceptor in the lumen.

It is not clear yet if there is a $\mathrm{Cu}$ chaperone for PAA2 in the stroma. In vitro experiments showed that CCS could interact with PAA2 and deliver $\mathrm{Cu}$ to stimulate ATPase activity of PAA2. The reported effect on the $\mathrm{V}_{\max }$ of PAA2 for CCS bound to $\mathrm{Cu}$ was small in comparison to only $\mathrm{Cu}^{+}$ions (Blaby-Haas et al., 2014). In addition, knock-out of CCS does not affect PC activity at all and CCS is also hardly expressed when $\mathrm{Cu}$ is below moderate availability due to miR398 regulation. Yet under these conditions PC still matures efficiently (Cohu et al., 2009). Because the CLP protease cleaves PAA2, it also cannot be excluded that the N-terminal $\mathrm{HMB}$ domain of PAA2 remains as a proteolytic fragment and this could be a chaperone for PAA2 in the stroma. But the free PAA2 $\mathrm{HMB}$ domain bound to $\mathrm{Cu}^{+}$did not stimulate PAA2 ATPase activity at all and did not display $\mathrm{Cu}$ transfer activity (Blaby-Haas et al., 2014). Perhaps PAA2 receives $\mathrm{Cu}$ from a low molecular weight chelator such as glutathione in the stroma. Indeed ATPase activity is observed for PAA2 with only $\mathrm{Cu}^{+}$ present and in a phosphorylation assay PAA2 displayed a much higher affinity for free $\mathrm{Cu}$ compared to PAA1, which requires a chaperone (Blaby-Haas et al., 2014; Sautron et al., 2015).

\section{EFFECTS OF COPPER-MICRORNAS ON CU DISTRIBUTION IN CHLOROPLASTS}

A potential miR408 target site is present in PAA2/HMA8 genes. However in Arabidopsis this site is not used (Bernal et al., 2012; Tapken et al., 2012). It seems likely that more indirect microRNA regulation via miR398 and miR1444 has important consequences for chloroplast $\mathrm{Cu}$ delivery to PC. To maintain growth and development of the photosynthetic apparatus during lower $\mathrm{Cu}$ availability, $\mathrm{Cu}$ delivery to PC should be prioritized. Induction of miR398 causes a drastic reduction in CCS and CSD2 protein expression whereas miR1444 will prevent PPO expression. This should allow remaining $\mathrm{Cu}$ in the stroma to be transported via PAA2 to PC (Burkhead et al., 2009). Could there be significance to the use of the TAT pathway by PPO? In agreement with its function in defense PPO is strongly induced by wounding. If PPO can pick up $\mathrm{Cu}$ in the stroma it would give plants a way to further prioritize $\mathrm{Cu}$ use in the emergency situation of biological attack. In such a case further maturation of PC is envisioned to be a lower priority.

\section{OUTSTANDING QUESTIONS}

The chloroplast $\mathrm{Cu}$ delivery system is now one of the bestunderstood trace metal delivery systems. However, several questions remain regarding the function of PAA1 and PAA2 as a system.

Firstly, alternative transport routes must exist for $\mathrm{Cu}$ in chloroplasts. All the tested paa1 and paa2 loss of function mutants are suppressed by elevated levels of $\mathrm{Cu}$ in the growth medium and suppression is more evident for paal mutants (Abdel-Ghany et al., 2005a). Because both sequence analyses and immunoblot analyses have shown that all paa1 alleles except for paa1-3 and all paa2 alleles are truly null mutants, the implication is that low affinity alternative $\mathrm{Cu}$ transport pathways must exist (Tapken et al., 2012; Blaby-Haas et al., 2014; Boutigny et al., 2014).

Another still puzzling observation is that paa1/paa2 double mutants are seedling lethal even when given extra $\mathrm{Cu}$ in the media (Abdel-Ghany et al., 2005a). This observation is puzzling because synthetic lethality for two independent loci can be taken as support for functions of the encoded gene products in parallel pathways. Both paa1 and paa2 mutants are not lethal on soil, 
both are suppressed by $\mathrm{Cu}$ feeding and according to our model the two proteins function in sequence and not in parallel. Could we be wrong and could PAA1 and PAA2 function in parallel in the same membrane? This would require mis-targeting in the chloroplast of a fraction of the "normally" envelope-localized PAA1 to thylakoids or vice versa of PAA2 to the envelope. Such "mis-targeting" might explain both the suppression by $\mathrm{Cu}$ and the lethal phenotype of the double mutant. Given that PAA1 requires interaction with $\mathrm{PCH} 1$ and that $\mathrm{PAA} 2$ cannot accept $\mathrm{Cu}$ from PCH1 (Blaby-Haas et al., 2014) it seems unlikely that mistargeted PAA1 or PAA2 could be functional. Similarly, modeling approaches have suggested that PAA2 but not PAA1 is suitable for $\mathrm{Cu}$ delivery to $\mathrm{PC}$ by direct docking between the transporter and apo-plastocyanin (Sautron et al., 2015). Rather, we favor the idea that loss of two high affinity transporters restricts $\mathrm{Cu}$ transport to the thylakoids so much that low affinity transport activities can no longer compensate (Abdel-Ghany et al., 2005a).

How did PAA1 and PAA2 evolve? The chloroplast has evolved via endosymbiosis from a cyanobacterial ancestor in which $\mathrm{Cu}$ also needed to be supplied to PC and to CCO in the same membrane. In the cyanobacterium Synechocystis PCC6803 two $\mathrm{Cu}$-transporters, $\mathrm{CtaA}$ and $\mathrm{PacS}$, and a $\mathrm{Cu}$ chaperone, ScAtx, have been described (Phung et al., 1994; Tottey et al., 2001, 2002). CtaA was thought to be located in the bacterial envelope inner membrane, ScAtx is cytosolic and PacS is in the thylakoid membrane (see Figure 3). It was proposed that CtaA functions as a $\mathrm{Cu}$ importer based on physiological measurements and $\mathrm{Cu}$ contents of mutant cells; and that PacS functions to transport $\mathrm{Cu}$ into the thylakoid lumen, which is important for PC maturation and the prevention of toxic effects of $\mathrm{Cu}$ in the bacterial cytosol (Tottey et al., 2001, 2002). Sequence comparisons show that both PAA1 and PAA2 are more similar to CtaA and thus PacS and ScAtx1 as well as COX seem to be lost from the chloroplast system after endosymbiosis (Abdel-Ghany et al., 2005a; Hanikenne and Baurain, 2014). The $\mathrm{V}_{\max }$ kinetic parameter measured for both PAA1 and PAA2 is comparable to that of CtaA and about 10-fold lower than the $\mathrm{V}_{\max }$ reported for PacS, which further supports the notion that PAA1 and PAA2 are more similar to CtaA (BlabyHaas et al., 2014). Thus, it can be proposed that both PAA1 and PAA2 are derived from a CtaA-like cyanobacterial sequence. Which steps would have been required for the evolution of the chloroplast $\mathrm{Cu}$-transporting P-type ATPases?

The scenario where $\mathrm{CtaA}$ functions as a $\mathrm{Cu}$ importer in the cyanobacterium (which is not as it is depicted by us in Figure 3) seems at first glance straightforward but there are, in our opinion, two issues with this model (Tottey et al., 2001, 2002). One is that CtaA in the cellular importer orientation should have a topology that is non-canonical from an evolutionary perspective in that it would have its ATP binding site not on the cytoplasmic side of the bacterial inner membrane but in the periplasm. Alternatively, CtaA could have its ATP binding site in the cytosol and import $\mathrm{Cu}$ toward its ATP binding site but in this case it would be the only $\mathrm{Cu}$-ATPase that transports toward the cytoplasm and it would require a unique mechanism (this we consider a very unlikely scenario). Therefore we favor the idea that CtaA has a toplogy as indicated in Figure 3. The other issue associated with CtaA functioning as an importer would be that PAA2, if indeed derived from a CtaA-like sequence, would have flipped its topology in the membrane to now have its ATP binding site in the stroma of the chloroplast (equivalent to the bacterial cytosol). It is hard to envision a mechanism for this. Is there another, perhaps more parsimonious scenario for the evolution of PAA1 and PAA2 from a CtaA-like sequence? We propose the model in Figure 3. In this scenario CtaA is in an orientation in the cyanobacterium where it serves a biosynthetic function that allows it to donate $\mathrm{Cu}$ to exoplasmic (non-cytosolic) $\mathrm{Cu}$ enzymes such as PC and CCO. In the case of COX maturation, perhaps copper chaperones are utilized equivalent to the well-described factors that mediate COX maturation in mitochondria in the intermembrane space (Carr and Winge, 2003). CtaA in the topology proposed by us might be located in the inner membrane of the envelope. In addition, or alternatively, CtaA is in a hypothetical internal vesicle that would allow it to also facilitate $\mathrm{Cu}$ delivery to $\mathrm{PC}$ and COX in the thylakoids via vesicular transport. We believe that the model in Figure 3 for CtaA function can be reconciled with all published data regarding phenotypes of cyanobacterial ctaA mutants and interactions with ScAtx (Tottey et al., 2001, 2002). For the evolution of PAA2 and PAA1 in chloroplasts we propose that they derive from a cyanobacterial CtaA protein perhaps present in an internal vesicle.

The model as depicted in Figure 3 also has apparent problems, but we think that these issues can all be resolved. First, the model in Figure 3 invokes that $\mathrm{Cu}$ enters the cyanobacterial cell via an alternative, not yet described, route. Low affinity yet somehow substantial $\mathrm{Cu}$ ion uptake by bacteria apparently does occur and is perhaps favored by the membrane potential and the high $\mathrm{Cu}$ chelating capacity of the cytosol relative to extracellular spaces. Indeed, many bacteria have extensive ATPdependent $\mathrm{Cu}$ extrusion systems required to avoid $\mathrm{Cu}$ toxicity even if they lack specific $\mathrm{Cu}$ import pathways (Outten et al., 2001). Another possible weakness of the model as presented in Figure 3 is that evidence for the types of vesicles that allow $\mathrm{Cu}$ trafficking is lacking in present day cyanobacteria. However, these types of vesicles would be by definition transient and we only need to invoke that an ancestor of the chloroplast utilized such vesicles. The final possible issue with the model now depicted in Figure 3 is that PAA1 would have a flipped topology relative to CtaA. However, we postulate that the presence of the poly glycine domain of PAA1 serves as an envelope retention signal that at the same time forces insertion of the transporter in the correct new orientation. A poly glycine containing stretch was postulated to serve as an envelope retention signal for chloroplast TOC75 protein (Inoue and Keegstra, 2003). The poly glycine-containing stretch is a hallmark of PAA1 proteins and not found in PAA2 homologs (Abdel-Ghany et al., 2005a; Blaby-Haas et al., 2014; Hanikenne and Baurain, 2014).

Another question is whether there also is a pathway for the export of $\mathrm{Cu}$ from plastids? To regulate ion $\mathrm{H}^{+}, \mathrm{Ca}^{2+}$, and $\mathrm{Na}^{+}$ion concentrations, cellular membrane systems are typically equipped with transport pathways for both directions. Indeed, in plants COPTs provide transport to the cytosol while HMA5 and 7 provide export. Is a similar scenario in place in the chloroplast? Is there a $\mathrm{Cu}$ exporter for thylakoids and the envelope membranes? In Chlamydomonas one additional function of PC next to 


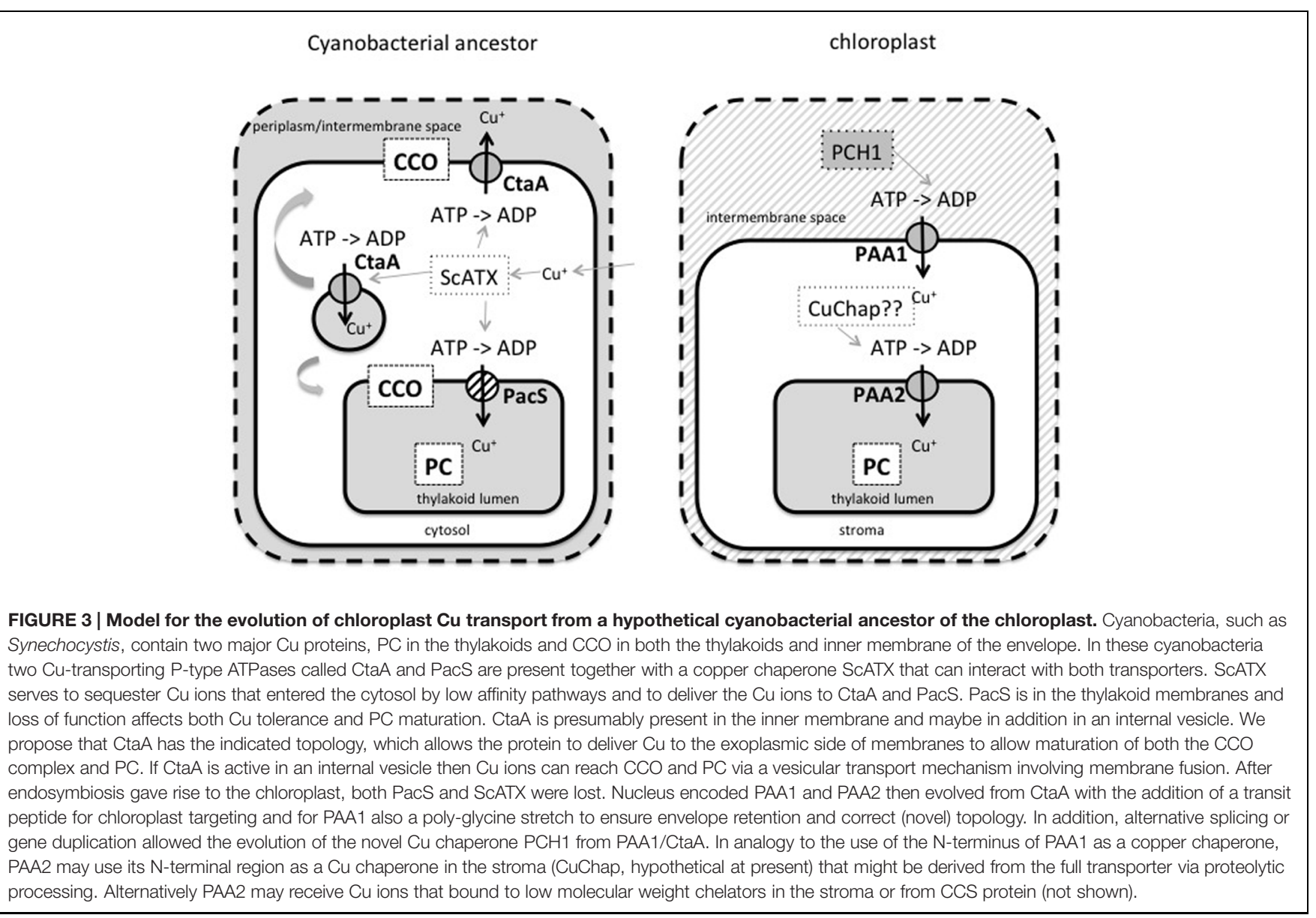

electron transport might be that it serves as a $\mathrm{Cu}$ store upon which the cell can rely in times of impending deficiency (Kropat et al., 2015). In this state, CRR1 mediates expression of the Fe containing functional PC alternative cytochrome- $c_{6}$ while PC expression is turned off and PC turnover induced, perhaps via a Deg-type protease (Kropat et al., 2015). The $\mathrm{Cu}$ coming out of PC can then be utilized for other functions such as CCO in mitochondria and ferric reductase activities at the cell surface (Kropat et al., 2015). This scenario would rely on $\mathrm{Cu}$ export from the thylakoids and chloroplasts. Similarly, during senescence in higher plants $\mathrm{Cu}$ from plastids might be re-purposed for use in seeds or storage in stem parts. For Arabidopsis it was estimated that less than $30 \%$ of $\mathrm{Cu}$ going to seeds comes from senescing rosettes, which might imply that $\mathrm{Cu}$ re-routing from plastids is a minor pathway (Waters et al., 2006). What could be the $\mathrm{Cu}$ exporter? The P-type ATPase HMA1 is located in chloroplast envelope membranes (Seigneurin-Berny et al., 2006). It was originally proposed that HMA1 protein functions in $\mathrm{Cu}$ homeostasis based on phenotypic characterization of yeast expressing recombinant HMA1 (Seigneurin-Berny et al., 2006). Furthermore, a lower $\mathrm{Cu}$ content and reduced stimulation of ATPase activity by $\mathrm{Cu}$ ions for chloroplasts isolated from plants that lack HMA1 was observed, which led to the suggestion that HMA1 might function as an alternative for PAA1 in mediating $\mathrm{Cu}$ import into plastids (Seigneurin-Berny et al., 2006). However, a careful analysis of paal/hmal double mutants suggests that HMA1 is unlikely to transport $\mathrm{Cu}$ into plastids since the double mutant is virtually identical to the single paal mutant for the maturation of both PC and CSD2 (Boutigny et al., 2014). Overexpression of HMA1 in different backgrounds caused higher $\mathrm{Cu}$ levels to be observed in chloroplasts of the paa1 mutant background but not in the wild-type background (Boutigny et al., 2014). We conclude that HMA1 affects Cu homeostasis somehow but the substrate (and direction of transport) for HMA1 remains unclear (see for a more extensive review and data on this topic see: Boutigny et al., 2014).

Another possible $\mathrm{Cu}$ export pathway might be formed by members of the YSL family, which was first described for its involvement in Fe acquisition. Recently two YSL members (YSL4 and 6) were described in the chloroplast envelope where they have a function in preventing Fe overload (Divol et al., 2013). Perhaps these proteins might also mediate some $\mathrm{Cu}$ export. Alternatively, $\mathrm{Cu}$ might be recycled from chloroplasts present in vacuoles following autophagy. Autophagy of plastids in lytic vacuoles might be an important mechanism to recycle precious micronutrients such as $\mathrm{Cu}$ and this field deserves more attention in the future (for a review see Blaby-Haas and Merchant, 2014).

Finally, a question is how $\mathrm{Cu}$ reaches the chloroplast surface, a question that is important to answer in view of the strong capacity of $\mathrm{Cu}$ to bind to proteins and thus to be 
sequestered in the cytosol (Burkhead et al., 2009). Perhaps cellular architecture should be considered here. Lysosomes, vacuoles and related compartments may play a role in providing $\mathrm{Cu}$ to the photosynthetic machinery. Under Zn deficiency, Clamydomonas sequesters $\mathrm{Cu}$ in a lysosome-related compartment, perhaps to prevent displacement of $\mathrm{Zn}$ with $\mathrm{Cu}$ in important $\mathrm{Zn}$ enzymes. This process is CRR1-dependent (Hong-Hermesdorf et al., 2014). It is not clear, however, if plants have a similar mechanism in place. The COPT5 transporter in the tonoplast membrane of plants allows $\mathrm{Cu}$ to re-enter the cytosolic $\mathrm{Cu}$ pool (GarciaMolina et al., 2011; Klaumann et al., 2011). COPT5 is especially important during $\mathrm{Cu}$ starvation, a condition where it can be envisioned that it is beneficial to recycle precious $\mathrm{Cu}$ from organelles that are no longer needed, or damaged. In plant cells, the vacuole takes up a large volume and many organelles including chloroplasts are seen under the microscope to be pressed to the side of the cell by the vacuole. Under low $\mathrm{Cu}$ availability, close contact between the tonoplast and chloroplast envelopes would be an especially advantageous arrangement for $\mathrm{Cu}$ delivery to plastids. A very short distance between COPT5 and

\section{REFERENCES}

Abdel-Ghany, S. E. (2009). Contribution of plastocyanin isoforms to photosynthesis and copper homeostasis in Arabidopsis thaliana grown at different copper regimes. Planta 229, 767-779. doi: 10.1007/s00425-008-0869-z

Abdel-Ghany, S. E., Muller-Moule, P., Niyogi, K. K., Pilon, M., and Shikanai, T. (2005a). Two P-type ATPases are required for copper delivery in Arabidopsis thaliana chloroplasts. Plant Cell 17, 1233-1251. doi: 10.1105/tpc.104.030452

Abdel-Ghany, S. E., Burkhead, J. L., Gogolin, K. A., Andres-Colas, N., Bodecker, J. R., Puig, S., et al. (2005b). AtCCS is a functional homolog of the yeast copper chaperone Ccs1/Lys7. FEBS Lett. 579, 2307-2312.

Abdel-Ghany, S. E., and Pilon, M. (2008). MicroRNA-mediated systemic downregulation of copper protein expression in response to low copper availability in Arabidopsis. J. Biol. Chem. 283, 15932-15945. doi: 10.1074/jbc.M801406200

Andres-Colas, N., Sancenon, V., Rodriguez-Navarro, S., Mayo, S., Thiele, D. J., Ecker, J. R., et al. (2006). The Arabidopsis heavy metal P-type ATPase HMA5 interacts with metallochaperones and functions in copper detoxification of roots. Plant J. 45, 225-236. doi: 10.1111/j.1365-313X.2005.02601.x

Arnon, D. I. (1949). COPPER ENZYMES IN ISOLATED CHLOROPLASTS. POLYPHENOLOXIDASE IN BETA VULGARIS. Plant Physiol. 24, 1-15.

Bernal, M., Casero, D., Singh, V., Wilson, G. T., Grande, A., Yang, H., et al. (2012). Transcriptome sequencing identifies SPL7-regulated copper acquisition genes FRO4/FRO5 and copper dependence of iron homeostasis in Arabidopsis. Plant Cell 24, 738-761. doi: 10.1105/tpc.111.090431

Bernal, M., Testillano, P. S., Alfonso, M., del Carmen Risueño, M., Picorel, R., and Yruela, I. (2007). Identification and subcellular localization of the soybean copper P1B-ATPase GmHMA8 transporter. J. Struct. Biol. 158, 46-58. doi: $10.1016 /$ j.jsb.2006.10.016

Blaby-Haas, C. E., and Merchant, S. S. (2014). Lysosome-related organelles as mediators of metal homeostasis. J. Biol. Chem. 289, 28129-28136. doi: 10.1074/jbc.R114.592618

Blaby-Haas, C. E., Padilla-Benavides, T., Stübe, R., Argüello, J. M., and Merchant, S. S. (2014). Evolution of a plant-specific copper chaperone family for chloroplast copper homeostasis. Proc. Natl. Acad. Sci. U.S.A. 111, E5480-E5487. doi: 10.1073/pnas.1421545111

Boutigny, S., Sautron, E., Finazzi, G., Rivasseau, C., Frelet-Barrand, A., Pilon, M., et al. (2014). HMA1 and PAA1, two chloroplast-envelope PIB-ATPases, play distinct roles in chloroplast copper homeostasis. J. Exp. Bot. 65, 1529-1540. doi: 10.1093/jxb/eru020

Burkhead, J. L., Reynolds, K. A., Abdel-Ghany, S. E., Cohu, C. M., and Pilon, M. (2009). Copper homeostasis. New Phytol. 182, 799-816. doi: 10.1111/j.14698137.2009.02846.x the chloroplast envelope surface would mean that $\mathrm{Cu}$ ions have to diffuse only a very small distance via outer membrane porins to reach $\mathrm{PCH} 1$ and PAA1 in the envelope and can virtually avoid the cytoplasm. It will be interesting to address these various questions in further research.

\section{AUTHOR CONTRIBUTIONS}

GA drafted the first manuscript. MP edited and finalized the MS.

\section{ACKNOWLEDGMENTS}

We thank Dr. Elizabeth Pilon-Smits for critical reading of the manuscript. Work in the authors' laboratory was supported by the Agriculture and Food Research Initiative competitive grant 2012-67-13-19416 of the USDA National Institute of Food and Agriculture and by the US National Science Foundation grant no MCB 1244142 to MP.

Carr, H. S., and Winge, D. R. (2003). Assembly of cytochrome c oxidase within the mitochondrion. Acc. Chem. Res. 36, 309-316. doi: 10.1021/ar0200807

Catty, P., Boutigny, S., Miras, R., Joyard, J., Rolland, N., and Seigneurin-Berny, D. (2011). Biochemical characterization of AtHMA6/PAA1, a chloroplast envelope Cu(I)-ATPase. J. Biol. Chem. 286, 36188-36197. doi: 10.1074/jbc.M111. 241034

Chen, C. C., Chen, Y. Y., Tang, I. C., Liang, H. M., Lai, C. C., Chiou, J. M., et al. (2011). Arabidopsis SUMO E3 ligase SIZ1 is involved in excess copper tolerance. Plant Physiol. 156, 2225-2234. doi: 10.1104/pp.111. 178996

Chu, C. C., Lee, W. C., Guo, W. Y., Pan, S. M., Chen, L. J., Li, H. M., et al. (2005). A copper chaperone for superoxide dismutase that confers three types of copper/zinc superoxide dismutase activity in Arabidopsis. Plant Physiol. 139, 425-436. doi: 10.1104/pp.105. 065284

Chu, H. H., Chiecko, J., Punshon, T., Lanzirotti, A., Lahner, B., Salt, D. E., et al. (2010). Successful reproduction requires the function of Arabidopsis Yellow Stripe-Like1 and Yellow Stripe-Like3 metalnicotianamine transporters in both vegetative and reproductive structures. Plant Physiol. 154, 197-210. doi: 10.1104/pp.110. 159103

Cohu, C. M., Abdel-Ghany, S. E., Reynolds, K. A. G., Onofrio, A. M., Bodecker, J. R., Kimbrel, J. A., et al. (2009). Copper delivery by the copper chaperone for chloroplast and cytosolic copper/zincsuperoxide dismutases: regulation and unexpected phenotypes in an Arabidopsis mutant. Mol. Plant 2, 1336-1350. doi: $10.1093 / \mathrm{mp} / \mathrm{ssp} 084$

Constabel, C. P., Yip, L., Patton, J. J., and Christopher, M. E. (2000). Polyphenol oxidase from hybrid poplar: cloning and expression in response to wounding and herbivory. Plant Physiol. 124, 285-295. doi: 10.1104/pp.124.1.285

Divol, F., Couch, D., Conéjéro, G., Roschzttardtz, H., Mari, S., and Curie, C. (2013). The Arabidopsis YELLOW STRIPE LIKE4 and 6 transporters control iron release from the chloroplast. Plant Cell 25, 1040-1055. doi: 10.1105/tpc.112.107672

Dugas, D. V., and Bartel, B. (2008). Sucrose induction of Arabidopsis miR398 represses two $\mathrm{Cu} / \mathrm{Zn}$ superoxide dismutases. Plant Mol. Biol. 67, 403-417. doi: 10.1007/s11103-008-9329-1

Eisses, J. F., and Kaplan, J. H. (2005). The mechanism of copper uptake mediated by human CTR1, a mutational analysis. J. Biol. Chem. 280, 37159-37168. doi: 10.1074/jbc.M508822200

Garcia-Molina, A., Andrés-Colás, N., Perea-García, A., Del Valle-Tascón, S., Peñarrubia, L., and Puig, S. (2011). The intracellular Arabidopsis COPT5 transport protein is required for photosynthetic electron transport under 
severe copper deficiency. Plant J. 65, 848-860. doi: 10.1111/j.1365-313X.2010. 04472.x

González-Guerrero, M., and Argüello, J. M. (2008). Mechanism of Cu+transporting ATPases: soluble $\mathrm{Cu}+$ chaperones directly transfer $\mathrm{Cu}+$ to transmembrane transport sites. Proc. Natl. Acad. Sci. U.S.A. 105, 5992-5997. doi: 10.1073/pnas.0711446105

Hanikenne, M., and Baurain, D. (2014). Origin and evolution of metal P-type ATPases in Plantae (Archaeplastida). Front. Plant Sci. 4:544. doi: 10.3389/fpls.2013.00544

Hirayama, T., Kieber, J. J., Hirayama, N., Kogan, M., Guzman, P., Nourizadeh, S., et al. (1999). RESPONSIVE-TO-ANTAGONIST1, a Menkes/Wilson diseaserelated copper transporter, is required for ethylene signaling in Arabidopsis. Cell 97, 383-386. doi: 10.1016/S0092-8674(00)80747-3

Hong-Hermesdorf, A., Miethke, M., Gallaher, S. D., Kropat, J., Dodani, S. C., Chan, J., et al. (2014). Subcellular metal imaging identifies dynamic sites of $\mathrm{Cu}$ accumulation in Chlamydomonas. Nat. Chem. Biol. 10, 1034-1042. doi: 10.1038/nchembio. 1662

Huang, C. H., Kuo, W. Y., Weiss, C., and Jinn, T. L. (2012). Copper chaperone-dependent and independent activation of three copper-zinc superoxide dismutase homologs localized in different cellular compartments in Arabidopsis. Plant Physiol. 158, 737-746. doi: 10.1104/pp.111.190223

Inoue, K., and Keegstra, K. (2003). A polyglycine stretch is necessary for proper targeting of the protein translocation channel precursor to the outer envelope membrane of chloroplasts. Plant J. 34, 661-669. doi: 10.1046/j.1365313X.2003.01755.x

Irving, H., and Williams, R. J. P. (1948). Order of stability of metal complexes. Nature 162, 746-747. doi: 10.1038/162746a0

Jarvis, P. (2008). Targeting of nucleus-encoded proteins to chloroplasts in plants. New Phytol. 179, 257-285. doi: 10.1111/j.1469-8137.2008.02452.x

Jung, H. I., Gayomba, S. R., Rutzke, M. A., Craft, E., Kochian, L. V., and Vatamaniuk, O. K. (2012). COPT6 is a plasma membrane transporter that functions in copper homeostasis in Arabidopsis and is a novel target of SQUAMOSA promoter-binding protein-like 7. J. Biol. Chem. 287, 3325233267. doi: 10.1074/jbc.M112.397810

Klaumann, S., Nickolaus, S. D., Fürst, S. H., Starck, S., Schneider, S., Ekkehard Neuhaus, H., et al. (2011). The tonoplast copper transporter COPT5 acts as an exporter and is required for interorgan allocation of copper in Arabidopsis thaliana. New Phytol. 192, 393-404. doi: 10.1111/j.1469-8137.2011.03798.x

Kliebenstein, D. J., Monde, R.-A., and Last, R. L. (1998). Superoxide dismutase in Arabidopsis: an eclectic enzyme family with disparate regulation and protein localization. Plant Physiol. 118, 637-650. doi: 10.1104/pp.118.2.637

Kropat, J., Gallaher, S. D., Urzica, E. I., Nakamoto, S. S., Strenkert, D., Tottey, S., et al. (2015). Copper economy in Chlamydomonas: prioritized allocation and reallocation of copper to respiration vs. photosynthesis. Proc. Natl. Acad. Sci. U.S.A. 112, 2644-2651. doi: 10.1073/pnas.1422492112

Kropat, J., Tottey, S., Birkenbihl, R. P., Depege, N., Huijser, P., and Merchant, S. (2005). A regulator of nutritional copper signaling in Chlamydomonas is an SBP domain protein that recognizes the GTAC core of copper response element. Proc. Natl. Acad. Sci. U.S.A. 102, 18730-18735. doi: 10.1073/pnas.05076 93102

Mandal, A. K., Yang, Y., Kertesz, T. M., and Argüello, J. M. (2004). Identification of the transmembrane metal binding site in $\mathrm{Cu}+$-transporting PIB-type ATPases. J. Biol. Chem. 279, 54802-54807. doi: 10.1074/jbc.M410854200

Mayer, M. (2006). Polyphenol oxidases in plants and fungi: going place? A review. Phytochemistry 67, 2318-2331. doi: 10.1016/j.phytochem.2006. 08.006

Milner, M. J., Seamon, J., Craft, E., and Kochian, L. V. (2013). Transport properties of members of the ZIP family in plants and their role in $\mathrm{Zn}$ and Mn homeostasis. J. Exp. Bot. 64, 369-381. doi: 10.1093/jxb/ers315

Outten, F. W., Huffman, D. L., Hale, J. A., and O'Halloran, T. V. (2001). The independent cue and cus systems confer copper tolerance during aerobic and anaerobic growth in Escherichia coli. J. Biol. Chem. 276, 30670-30677. doi: 10.1074/jbc.M104122200

Pesaresi, P., Scharfenberg, M., Weigel, M., Granlund, I., Schröder, W. P., Finazzi, G., et al. (2009). Mutants, overexpressors, and interactors of Arabidopsis plastocyanin isoforms: revised roles of plastocyanin in photosynthetic electron flow and thylakoid redox state. Mol. Plant 2, 236-248. doi: 10.1093/mp/ssn041
Phung, L. T., Ajlani, G., and Haselkorn, R. (1994). P-type ATPase from the cyanobacterium Synechococcus 7942 related to the human Menkes and Wilson disease gene products. Proc. Natl. Acad. Sci. U.S.A. 91, 9651-9654. doi: 10.1073/pnas.91.20.9651

Pufahl, R. A., Singer, C. P., Peariso, K. L., Lin, S. J., Schmidt, P. J., Fahrni, C. J., et al. (1997). Metal ion chaperone function of the soluble $\mathrm{Cu}(\mathrm{I})$ receptor Atx1. Science 278, 853-856. doi: 10.1126/science.278.5339.853

Puig, S., Mira, H., Dorcey, E., Sancenon, V., Andres-Colas, N., Garcia-Molina, A., et al. (2007). Higher plants possess two different types of ATX1-like copper chaperones. Biochem. Biophys. Res. Commun. 354, 385-390. doi: 10.1016/j.bbrc.2006.12.215

Rae, T. D., Schmidt, P. J., Pufahl, R. A., Culotta, V. C., and O'Halloran, T. V. (1999). Undetectable intracellular free copper: the requirement of a copper chaperone for superoxide dismutase. Science 284, 805-808. doi: 10.1126/science.284.5415.805

Ravet, K., Danford, F. L., Dihle, A., Pittarello, M., and Pilon, M. (2011). Spatiotemporal analysis of Copper homeostasis in Populus trichocarpa reveals an integrated molecular remodeling for a preferential allocation of Copper to plastocyanin in the chloroplasts of developing leaves. Plant Physiol. 157, 1300-1312. doi: 10.1104/pp.111.183350

Rizhsky, L., Liang, H., and Mittler, R. (2003). The water-water cycle is essential for chloroplast protection in the absence of stress. J. Biol. Chem. 278, 38921-38925. doi: 10.1074/jbc.M304987200

Rosenzweig, A. C., and Argüello, J. M. (2012). Toward a molecular understanding of metal transport by P(1B)-type ATPases. Curr. Top. Membr. 69, 113-136. doi: 10.1016/B978-0-12-394390-3.00005-7

Sancenon, V., Pui, S., Mira, H., Thiele, D. J., and Penarrubia, L. (2003). Identification of a copper transporter family in Arabidopsis thaliana. Plant Mol. Biol. 51, 577-587. doi: 10.1023/A:1022345507112

Sancenón, V., Puig, S., Mateu-Andrés, I., Dorcey, E., Thiele, D. J., and Peñarrubia, L. (2004). The Arabidopsis copper transporter COPT1 functions in root elongation and pollen development. J. Biol. Chem. 279, 15348-15355. doi: 10.1074/jbc.M313321200

Sautron, E., Mayerhofer, H., Giustini, C., Pro, D., Crouzy, S., Ravaud, S., et al. (2015). HMA6 and HMA8 are two chloroplast $\mathrm{Cu}+$-ATPases with different enzymatic properties. Biosci. Rep. 35, e00201. doi: 10.1042/BSR201 50065

Schubert, M., Petersson, U. A., Haas, B. J., Funk, C., Schröder, W. P., and Kieselbach, T. (2002). Proteome map of the chloroplast lumen of Arabidopsis thaliana. J. Biol. Chem. 277, 8354-8365. doi: 10.1074/jbc.M10857 5200

Seigneurin-Berny, D., Gravot, A., Auroy, P., Mazard, C., Kraut, A., Finazzi, G., et al. (2006). HMA1, a new Cu-ATPase of the chloroplast envelope, is essential for growth under adverse light conditions. J. Biol. Chem. 281, 2882-2892. doi: 10.1074/jbc.M508333200

Shikanai, T., Muller-Moule, P., Munekage, Y., Niyogi, K. K., and Pilon, M. (2003). PAA1, a P-type ATPase of Arabidopsis, functions in copper transport in chloroplasts. Plant Cell 15, 1333-1346. doi: 10.1105/tpc.011817

Smeekens, S., Bauerle, C., Hageman, J., Keegstra, K., and Weisbeek, P. (1986). The role of the transit peptide in the routing of precursors toward different chloroplast compartments. Cell 46, 365-375. doi: 10.1016/0092-8674(86) 90657-4

Sunkar, R., Kapoor, A., and Zhu, J. K. (2006). Posttranscriptional induction of two $\mathrm{Cu} / \mathrm{Zn}$ superoxide dismutase genes in Arabidopsis is mediated by downregulation of miR398 and important for oxidative stress tolerance. Plant Cell 18, 2051-2065. doi: 10.1105/tpc.106.041673

Tapken, W., Kim, J., Nishimura, K., van Wijk, K. J., and Pilon, M. (2015a). The Clp protease system is required for copper ion-dependent turnover of the PAA2/HMA8 copper transporter in chloroplasts. New Phytol. 205, 511-517. doi: 10.1111/nph.13093

Tapken, W., Ravet, K., Shahbaz, M., and Pilon, M. (2015b). Regulation of $\mathrm{Cu}$ delivery to chloroplast proteins. Plant Signal. Behav. 10, e1046666. doi: 10.1080/15592324.2015.1046666

Tapken, W., Ravet, K., and Pilon, M. (2012). Plastocyanin controls the stabilization of the thylakoid Cu-transporting P-type ATPase PAA2/HMA8 in response to low copper in Arabidopsis. J. Biol. Chem. 287, 18544-18550. doi: 10.1074/jbc.M111.318204 
Tomizioli, M., Lazar, C., Brugière, S., Burger, T., Salvi, D., Gatto, L., et al. (2014). Deciphering thylakoid sub-compartments using a mass spectrometrybased approach. Mol. Cell. Proteomics 13, 2147-2167. doi: 10.1074/mcp.M114. 040923

Tottey, S., Rich, P. R., Rondet, S. A. M., and Robinson, N. J. (2001). Two Menkestype ATPases supply copper for photosynthesis in Synechocystis PCC6803. J. Biol. Chem. 276, 19999-20004. doi: 10.1074/jbc.M011243200

Tottey, S., Rondet, S. A., Borrelly, G. P., Robinson, P. J., Rich, P. R., and Robinson, N. J. (2002). Acopper metallochaperone for photosynthesis and respiration reveals metal-specific targets, interaction with an importer, and alternative sites for copper acquisition. J. Biol. Chem. 277, 5490-5497. doi: 10.1074/jbc.M105857200

Waldron, K. J., Rutherford, J. C., Ford, D., and Robinson, N. J. (2009). Metalloproteins and metal sensing. Nature 460, 823-830. doi: 10.1038/nature 08300

Wang, J., and Constabel, C. P. (2004). Polyphenol oxidase overexpression in transgenic Populus enhances resistance to herbivory by forest tent caterpillar (Malacosoma disstria). Planta 220, 87-96. doi: 10.1007/s00425-00 4-1327-1

Waters, B. M., Chu, H. H., Didonato, R. J., Roberts, L. A., Eisley, R. B., Lahner, B., et al. (2006). Mutations in Arabidopsis yellow stripe-like1 and yellow stripe-like3 reveal their roles in metal ion homeostasis and loading of metal ions in seeds. Plant Physiol. 141, 1446-1458. doi: 10.1104/pp.106.08 2586

Weigel, M., Varotto, C., Pesaresi, P., Finazzi, G., Rappaport, F., Salamini, F., et al. (2003). Plastocyanin is indispensable for photosynthetic electron flow in Arabidopsis thaliana. J. Biol. Chem. 278, 31286-31289. doi: 10.1074/jbc.M302876200
Williams, L. E., Pittman, J. K., and Hall, J. L. (2000). Emerging mechanisms for heavy metal transport in plants. Biochim. Biophys. Acta 1465, 104-126. doi: 10.1016/S0005-2736(00)00133-4

Wintz, H., Fox, T., Wu, Y. Y., Feng, V., Chen, W., Chang, H. S., et al. (2003). Expression profiles of Arabidopsis thaliana in mineral deficiencies reveal novel transporters involved in metal homeostasis. J. Biol. Chem. 278, 47644-47653. doi: 10.1074/jbc.M309338200

Yamasaki, H., Abdel-Ghany, S. E., Cohu, C. M., Kobayashi, Y., Shikanai, T., and Pilon, M. (2007). Regulation of copper homeostasis by micro-RNA in Arabidopsis. J. Biol. Chem. 282, 16369-16378. doi: 10.1074/jbc.M700138200

Yamasaki, H., Hayashi, M., Fukazawa, M., Kobayashi, Y., and Shikanai, T. (2009). SQUAMOSA promoter binding Protein-Like7 is a central regulator for copper homeostasis in Arabidopsis. Plant Cell 21, 347-361. doi: 10.1105/tpc.108.060137

Zheng, L., Yamaji, N., Yokosho, K., and Ma, J. F. (2012). YSL16 is a phloem-localized transporter of the copper-nicotianamine complex that is responsible for copper distribution in rice. Plant Cell 24, 3767-3782. doi: $10.1105 /$ tpc. 112.103820

Conflict of Interest Statement: The authors declare that the research was conducted in the absence of any commercial or financial relationships that could be construed as a potential conflict of interest.

Copyright (c) 2016 Aguirre and Pilon. This is an open-access article distributed under the terms of the Creative Commons Attribution License (CC BY). The use, distribution or reproduction in other forums is permitted, provided the original author(s) or licensor are credited and that the original publication in this journal is cited, in accordance with accepted academic practice. No use, distribution or reproduction is permitted which does not comply with these terms. 